\title{
Ore delineation by crosshole seismics, transmission and reflection imaging at Voisey's Bay, Canada
}

\author{
Calin Cosma and Nicoleta Enescu \\ Vibrometric, 10 Cuthbert Cres., Toronto, ON, M4S2H1, Canada.
}

\begin{abstract}
Three pairs of diamond drillholes were surveyed at Voisey' Bay, Labrador, Canada, in the Eastern Deeps deposit. The surveys were carried out in NQ diameter drillholes, which were approximately $800-850 \mathrm{~m}$ in length. The holes were nearly vertical and hole-to-hole distances ranged from $45 \mathrm{~m}$ to $80 \mathrm{~m}$. The p-wave velocity tomography surveys were designed to outline the morphology and continuity of the massive sulphide zone. Reflection imaging was also applied; to confirm whether this method could be used in conjunction with transmission tomography to expand the panel images to a volume. Confidence in the continuity of the massive sulphide zone is crucial since the relatively small massive zone contains a large portion of the metal in the Eastern Deeps deposit. Based on the results of these surveys, further sulphide delineation using surface exploration drillholes may be possible before underground exploration and development.
\end{abstract}

\section{Introduction}

For delineating $\mathrm{Ni}-\mathrm{Cu}$ sulphide mineralization, a combination of core logging and seismic data may offer an efficient and reliable way to infer the extent, shape, continuity and tenor of the ore. Core logs provide accurate data on the type and grade of the sulphide; however, gaining confidence by increasing the drillhole density can be costly and time consuming. Crosshole seismic imaging is emerging as a viable technique for improving the delineation of sulphide bodies between drillholes.

A crosshole seismic study has been conducted in the Eastern Deeps, a part of the Voisey's Bay Ni-Cu-Co deposits located in Labrador, Canada. In a related study, several drillholes in the Eastern Deeps deposit were logged with a full-waveform sonic tool and p-wave velocity as a function of depth was determined. This study indicated that the velocity of unmineralized host rock ranges from $5000 \mathrm{~m} / \mathrm{s}$ to $6800 \mathrm{~m} / \mathrm{s}$, while the velocity of the massive sulphide zone ranges from $4000 \mathrm{~m} / \mathrm{s}$ to $4500 \mathrm{~m} / \mathrm{s}$. Since the massive sulphide zone is anomalous in velocity compared to the host rock, crosshole seismic tomography is the technique of choice for delineation of this type of material. However, the image obtained by transmission tomography is two-dimensional and confined to the region between two holes.

Expanding the imaging exercise to a volume can be achieved by correlating two-dimensional representations obtained between pairs belonging to a larger set of adjacent boreholes and by performing crosshole reflection imaging in addition to transmission. The applicability of reflection imaging was somewhat uncertain because of the inverse variation of the velocity and density of the ore, higher density and lower velocity, with respect to surrounding rocks. A low contrast of acoustic impedance was therefore expected. In deed, attempts with 
classic Kirchhoff migration produced modest results. A migration technique based on the IP transform (Cosma et al., 2002) was applied, which decreased significantly the migration artifacts.

\section{Geology}

The Voisey's Bay Ni-Cu-Co deposits are associated with Middle Proterozoic troctolite bodies that intrude Archean quartz-feldspar-biotite gneiss of the Nain Province as well as Early Proterozoic garnetiferous paragneiss (Tasiuyak Gneiss) of the Churchill Province.

The Voisey's Bay troctolite intrusions comprise two large bodies, one overlying the Eastern Deeps deposit and the other underlying the Reid Brook Zone and the Eastern Deeps deposit. A "feeder dyke" or "conduit" extends north of the Eastern Deeps as well as to the west through the area of the Ovoid, Discovery Hill Zone and Reid Brook Zone. This dyke appears to link the two troctolite bodies described above.

Immediately southeast of the Ovoid, the troctolite body overlying the Eastern Deeps broadens into a large intrusion with a steep, south-dipping, northern contact with the gneisses. The base of the troctolite body dips $25^{\circ}$ southeast with a thickness of $400 \mathrm{~m}$ at its western margin, gradually thickening to about $1 \mathrm{~km}$ in the east. Its overall known width is approximately $1500 \mathrm{~m}$. A 30 - $50 \mathrm{~m}$ thick troctolite dyke extends northward from the main body of troctolite; this has been interpreted as a feeder for the main body of the troctolite and is believed to be the conduit through which the Eastern Deeps mineralization was transported.

The Eastern Deeps deposit occurs at the base of this intrusion, adjacent to the feeder, at depths between $650 \mathrm{~m}$ and $1000 \mathrm{~m}$ (Figure 1). The deposit follows the base of the troctolite and dips uniformly to the southeast at approximately $20^{\circ}-30^{\circ}$.
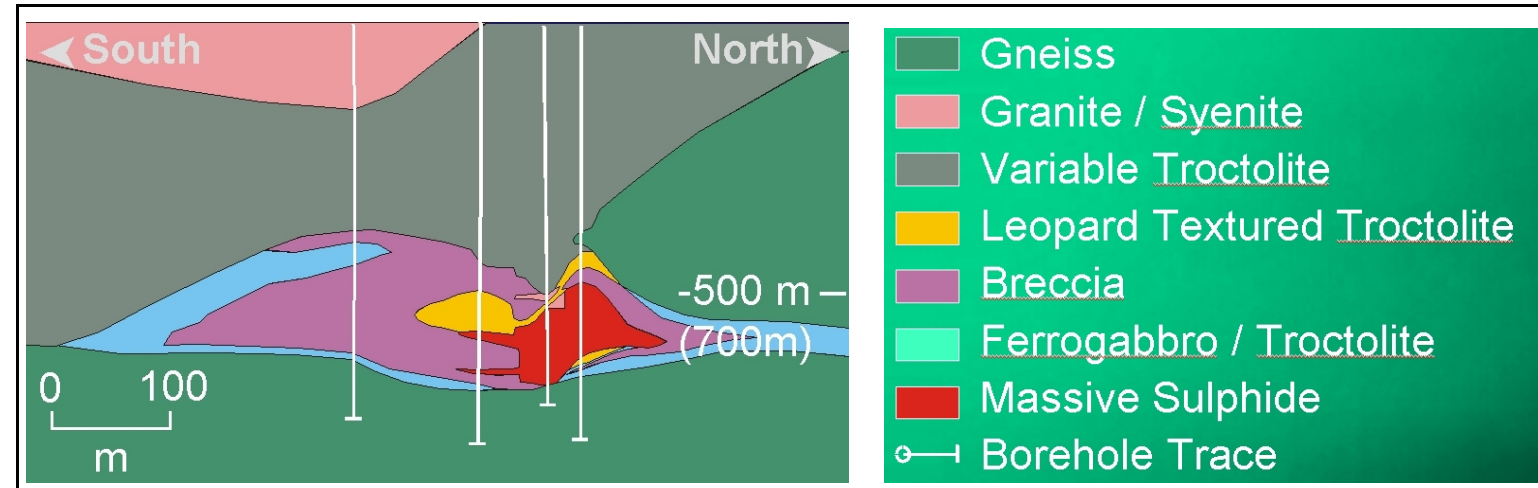

Figure 1: Geology of the Voisey's Bay deposit-Eastern Deeps cross-section.

Generally, massive sulphide occurs directly below the variable troctolite unit (a medium grained to pegmatitic troctolite to olivine gabbro containing partially digested gneissic fragments). Locally, there is an overlying unit of net-textured sulphides above the massive mineralization. The massive mineralization occurs as a single lens approximately $1.5 \mathrm{~km}$ in length, tapering towards the margins. Its maximum width is $200 \mathrm{~m}$, but the average width is 100 $\mathrm{m}$. The average thickness of the massive ore is approximately $20-30 \mathrm{~m}$, however, thicknesses of 
up to 54 m exist. More detailed geological information on Voisey's Bay can be found in the paper by Evans-Lamswood et al., 2000.

\section{Crosshole measurements and instrumentation}

The apparatus used at Voisey's Bay consists of a piezoelectric source based on the Swept Impact Seismic Technique (SIST - Park et al. 1996) and a string of 24 hydrophones (Figure 2a and Figure 2d, respectively). The SIST system produces sweeps of seismic pulses, i.e. rapid sequences with a monotonically varying pulse rate (Figure $3 \mathrm{~b}$ ). Because the time interval between any adjacent pulses is non-repeatable, a long sequence of impacts can be deconvolved into a short seismic record (Figure 3c), which contains all the energy emitted during the long sequence. With the SIST, the frequency band of each impact remains essentially the same, while the frequency of the impacts is varied. At Voisey's Bay, each record was obtained from a sequence of approximately 1500 impacts.

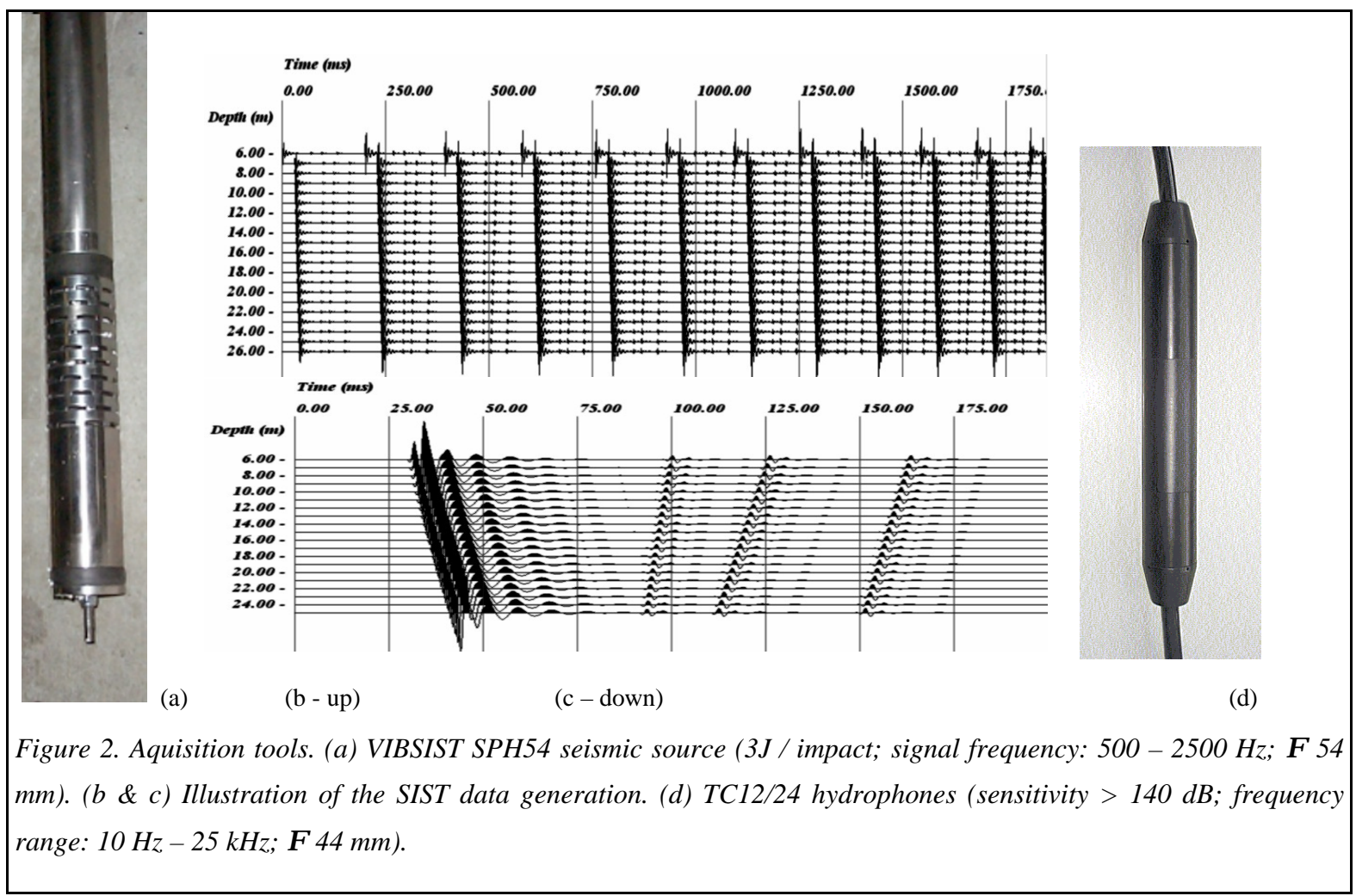

The crosshole seismic measurements were performed in three vertical sections, from drillhole A (common to all three sections) to drillholes B, C and D. The measurements were conducted at depths varying from approximately $540 \mathrm{~m}$ to $770 \mathrm{~m}$. The station increment was 0.5 $\mathrm{m}$ in the area judged as being of maximum interest and $1 \mathrm{~m}$ elsewhere, for both sources and receivers. A total of 16200 traces were recorded for each section. The useful signal is 
concentrated in the $500-2500 \mathrm{~Hz}$ band. At depths where the signals display travel time anomalies the data is also anomalous in frequency.

\section{Tomographic reconstruction with positioning constraints}

To produce a resolved and reliable image, the crosshole tomographic method requires that the positions of the sources and receivers are determined very accurately. In practice, keeping the positioning errors to the level required by the tomographic method may prove to be a difficult task.

Source and receiver positioning errors can occur because of drillhole deviations that are unaccounted for and/or incorrect source and receiver depths. These are related to a number of basic geometrical biases and compensated accordingly:

- Erroneous collar locations : relative lateral translations of drillholes

-Errors in determining the start azimuth of the drillholes: rotations of the drillholes with respect to the collar positions;

- Cable stretch and depth encoder calibration errors : stretch and shift along the drillholes,

- Errors generated by incremental drillhole orientation determinations: drillhole bending.

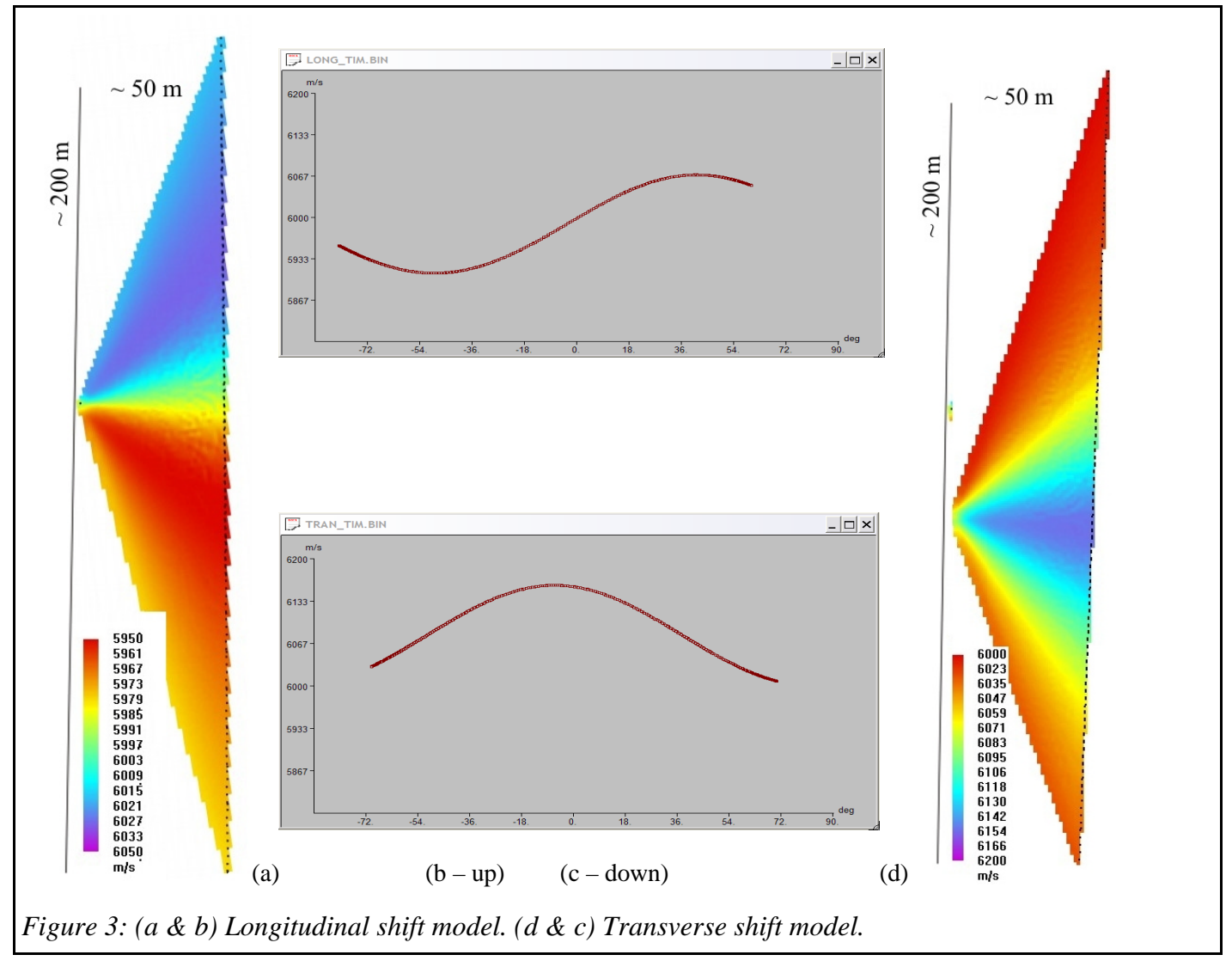


Figure 3 shows two examples of artifacts generated by positioning errors: longitudinal stretch and shift (Figure 3a and 3b) and lateral translation (Figure 3c and 3d). Figures 3a and 3d show corrupted tomographic reconstructions of single shot gathers, for a constant velocity of $6000 \mathrm{~m} / \mathrm{s}$ and position errors of $1 \mathrm{~m}$, longitudinal and transversal respectively. Figures $3 \mathrm{~b}$ and $3 \mathrm{c}$ depict the erroneous variations of the velocity with angle of the source-receiver trajectory. Both of these variations mimic false anisotropic behaviors. The magnitude of the would-be anisotropy is approximately $2.5 \%-3.0 \%$ in both cases.

Anisotropic distributions of $2.5 \%-3.0 \%$ were noticed in the Voisey' Bay data. Attempts were made to correct the data by means of a transversely isotropic model, but the tomographic inversions obtained with the corrected data produced a poor fit along the boreholes with the acoustic velocity logs. Alternatively, distance residuals were generated while performing tomographic inversions and used to further correct the positions of the drillholes.

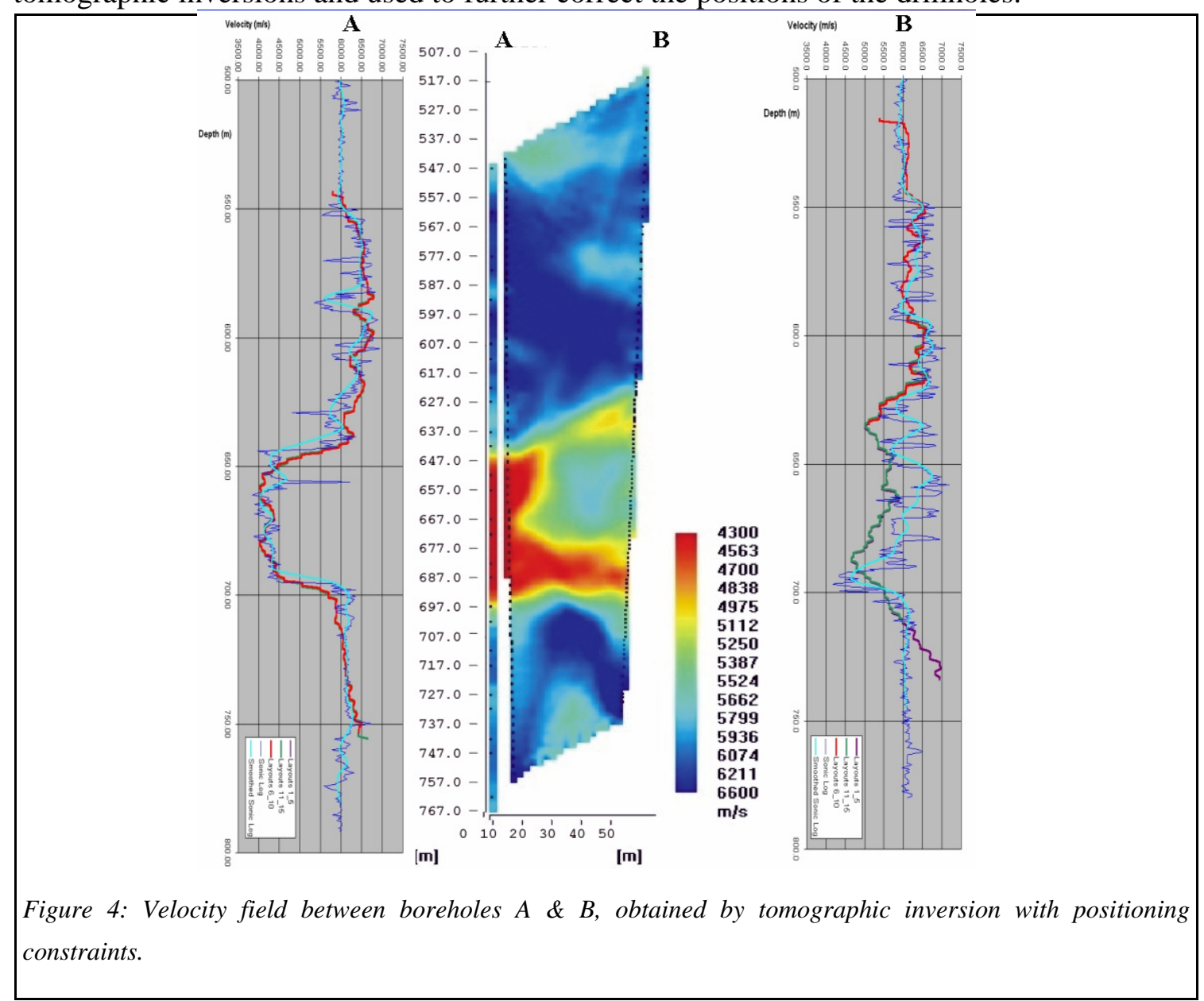

These lead to a very well resolved image of the ore body. Moreover, the velocity vs. depth functions in the two drill holes derived from smoothed acoustic logs and crosshole tomography agreed well (Figure 4), which they don't if anisotropic corrections are used instead of position corrections. 


\section{Reflection imaging}

The IP migration associates travel time functions to planar reflector elements. This may help avoiding known difficulties with Kirchhoff migration, e.g. when reflectors make steep angles with the survey layout. As IP migration operates with elements of plane, three parameters are carried through the migration: the center of the element, the dip and the azimuth.

A crosshole shot gather migrated along given dip and azimuth values has a similar geometry with a CDP transformed shot gather, except that in the IP case only reflector elements that meet the dip-azimuth condition are retained. The main difference between the IP migration and the CDP transform explained by (Wyatt and Wyatt, 1984) lays in the fact that with the IP migration the reflection points are computed directly in 3-D and a constant velocity is not required, the travel time functions being computable, in principle, for any velocity model. For each pair of dip-azimuth values, a 1-dimensional variety is constructed to represent the locus of a class of image sources. The locus of the reflection points associated with the set of images and the linear array of detectors forms a 2-dimensional variety, which is not necessarily a plane. Therefore, although the dip and azimuth have constant values, the migrated profiles obtained from crosshole shot gathers are folded and twisted because they do not depict zero-offset sections or volumes.

Another limitation with CDP, namely that the transform does not handle properly data corresponding to other dips and strikes than the value assumed, is elegantly solved by the IP migration, because other orientations than the ones permitted are suppressed by IP filtering.

\section{Results}

Figure 5a shows the P-wave velocity tomographic reconstructions of the three panels measured. The thick lines mark the intersections with massive sulphide and apparently match closely the low velocity zones. Figures $5 \mathrm{~b}$ and $5 \mathrm{c}$ present 3 -D views of the panels from two different angles and are meant to illustrate the match and continuity of the low velocity features from one panel to another.

The seismic sections between drill holes $\mathrm{A}$ and $\mathrm{C}$ and between drill holes $\mathrm{A}$ and $\mathrm{D}$ indicated more massive sulphide between the drill holes than was modeled initially. 


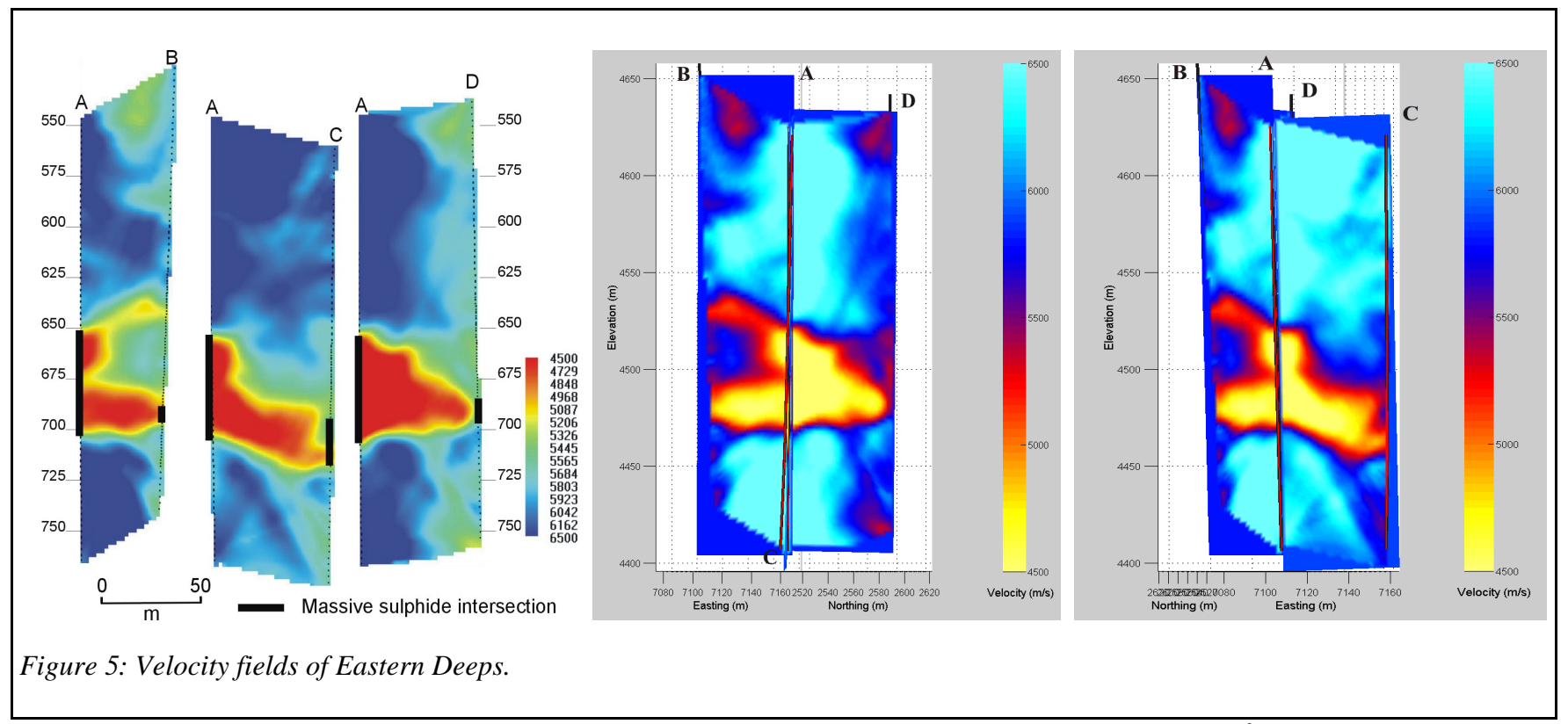

Figure 6a shows four migrated shotgathers, with an azimuth increment of $90^{\circ}$. The dip range is $0^{\circ}-30^{\circ}$ for each azimuth. To obtain Figure $6 \mathrm{~b}$, segments of migrated profiles were projected on the plane fitting best the two boreholes. This particular azimuth was selected to permit a direct comparison with the tomographic velocity image of Figure 6c. Reflection images can however be obtained along any chosen azimuth, or even as a migrated volume.

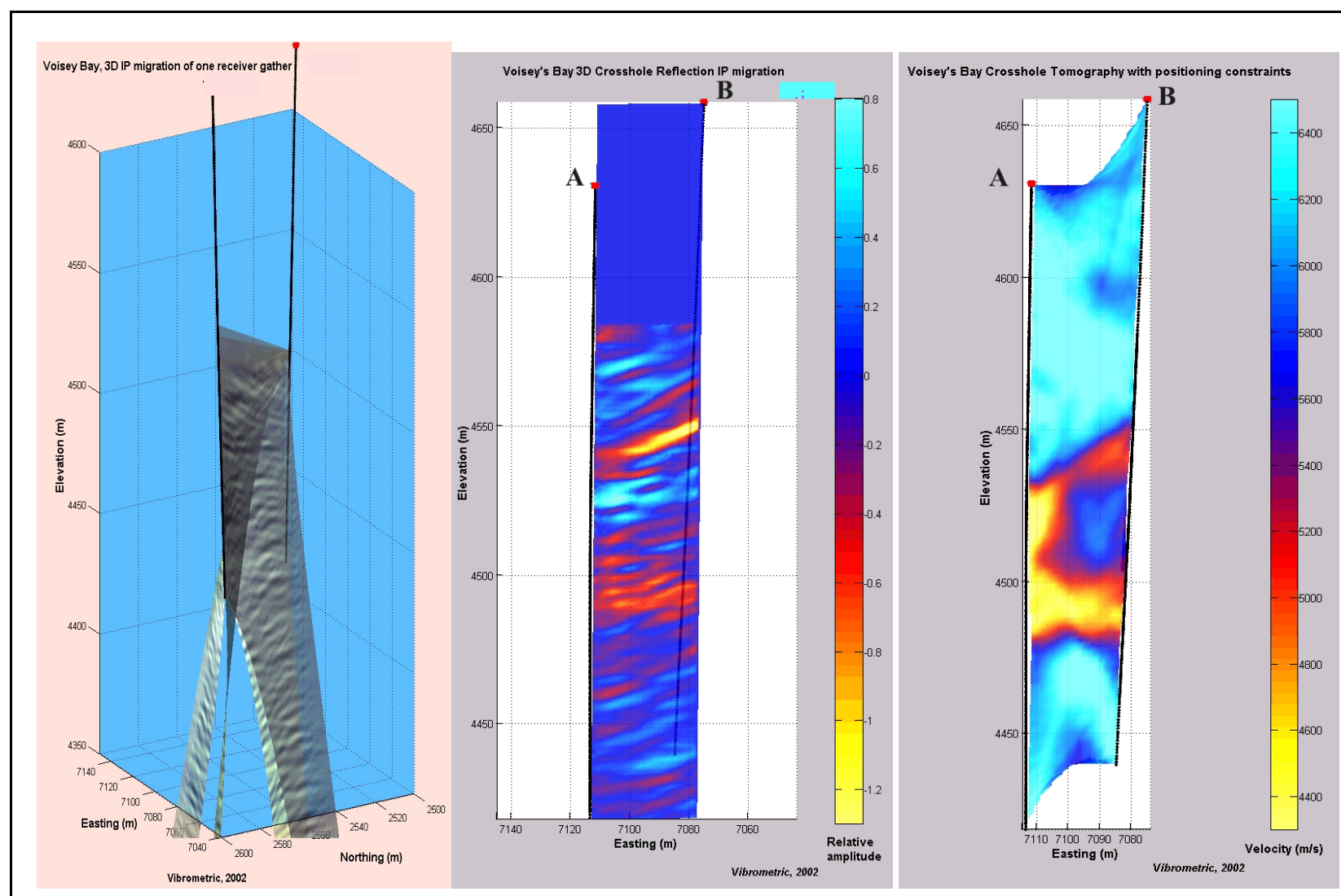

Figure 6: (a) Four migrated shotgathers, with an azimuth increment of $90^{\circ}$.(b) 3D IP migrated section. (c) Velocity field. 


\section{Conclusions}

Seismic tomography appears to detect massive sulphide zones reasonably well. From a mine planner's point of view, more work seems however to be needed to resolve the tenor of disseminated and semi-massive sulphide mineralization. With proper calibration it may be possible to differentiate between disseminated, semi-massive and massive sulphide.

An appropriate amount of crosshole seismic surveying may reduce the amount of drilling required in various stages of resource estimation. This may result in significant savings in exploration expenditures. Crosshole seismic surveys conducted from surface may also reduce the scope and cost of underground exploration programs.

The results obtained with reflection imaging projected on the plane of the crosshole section and the crosshole P-wave velocity tomography depict similar features but more work needs to be done to integrate fully 3-D reflection imaging and 2-D transmission tomography.

\section{Acknowledgement}

This study has been made possible by the kind contribution of Alan King, Glenn McDowell and Cameron Bell, of Inco Technical Services Ltd., Sudbury - Canada, who supported our efforts and shared with us their knowledge of the Voisey's Bay deposit.

\section{References}

Cosma C, Enescu N., 2001 Characterization of fractured rock in the vicinity of tunnels by the swept impact seismic technique. International journal of rock mechanics \& Mining Sciences, 38(2001) p. 815-821.

Cosma, C., Enescu, N., Adam, E., \& Balu, L. 2002. Vertical and horizontal seismic profiling investigations at Olkiluoto, 2001. Posiva Report 2002-xx, 194 p.

Evans-Lamswood, D.M., Butt, D.P., Jackson, R.S., Lee, D.V., Muggridge, M.G., Wheeler, R.I. and Wilton, D.H.C., 2000. Physical controls associated with the distribution of sulfides in the Voisey's Bay Ni-Cu-Co deposit, Labrador. Economic Geology, 95, no. 4, p. 749-769.

Park, C.B., Miller, R.D., Steeples, D.W. and Black, R.A., 1996. Swept Impact Seismic Technique (SIST). Geophysics, 61, no. 6, p. 1789 - 1803.

Wyatt, K.D., and Wyatt, S.B. 1984. Determining subsurface structure using the vertical seismic profile. In Vertical Seismic Profiling, Part B: Advanced Concepts, edited by M.N. Toksoz and R. Stewart. Geophysical Press, London, 419 p. 